\title{
FAST PYROLYSIS AS A PRECURSOR OF BTL
}

\author{
Juan Miguel Mesa Pérez, José Dílcio Rocha, \\ Luis Augusto Barbosa Cortez and Rodrigo Aparecido Jordan
}

\section{INTRODUCTION}

Fast Pyrolysis is a thermochemical biomass conversion process. Its feature is the thermal degradation of the solid fuel in the absence of oxygen in a short reaction time, in just a few seconds.

The main product obtained from a biomass pyrolysis process is the bio-oil, but there is also tproduction of charcoal powder, acid extract and gases.

Figure 1 shows the physical appearance of the pyrolysis products of the sugarcane trash pro- cessed in the Fast Pyrolysis Plant with a capacity of $200 \mathrm{~kg} / \mathrm{h}$ of biomass. This technology based on fluidized bed was developed at Feagri-Unicamp in partnership with the Bioware, a company incubated and graduated from Incamp (Incubator of Unicamp). The equipment construction of the pilot plant was done by Termoquip Energia Alternativa Ltda (<http://www.termoquip.com.br>).

Other product of this technology, the gases, is not showed on Figure 1, because these gases are burned and reused on its own production system.

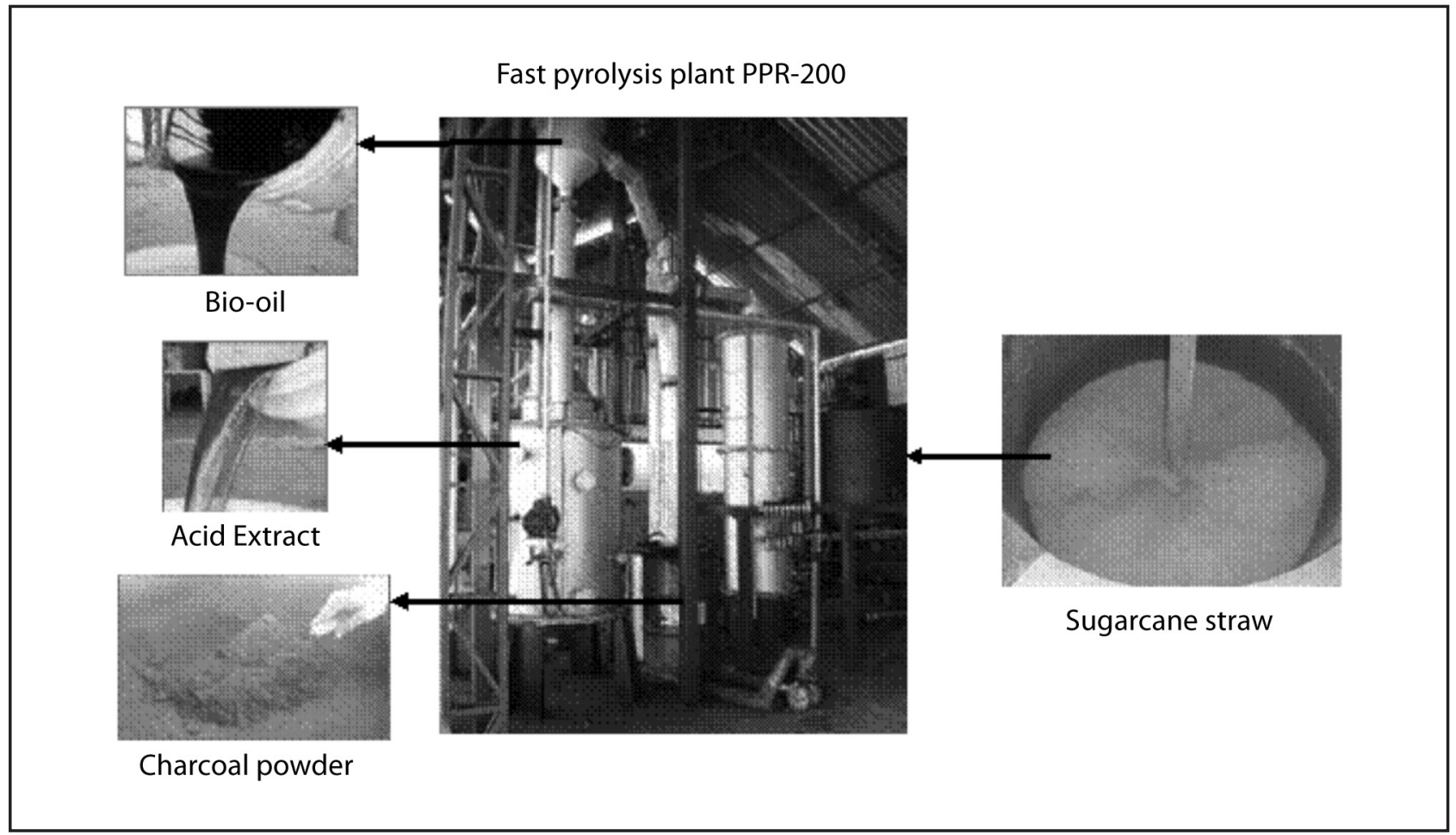

FIGURE 1 Feagri-Unicamp demonstration plant, the utilized raw material and obtained products. 


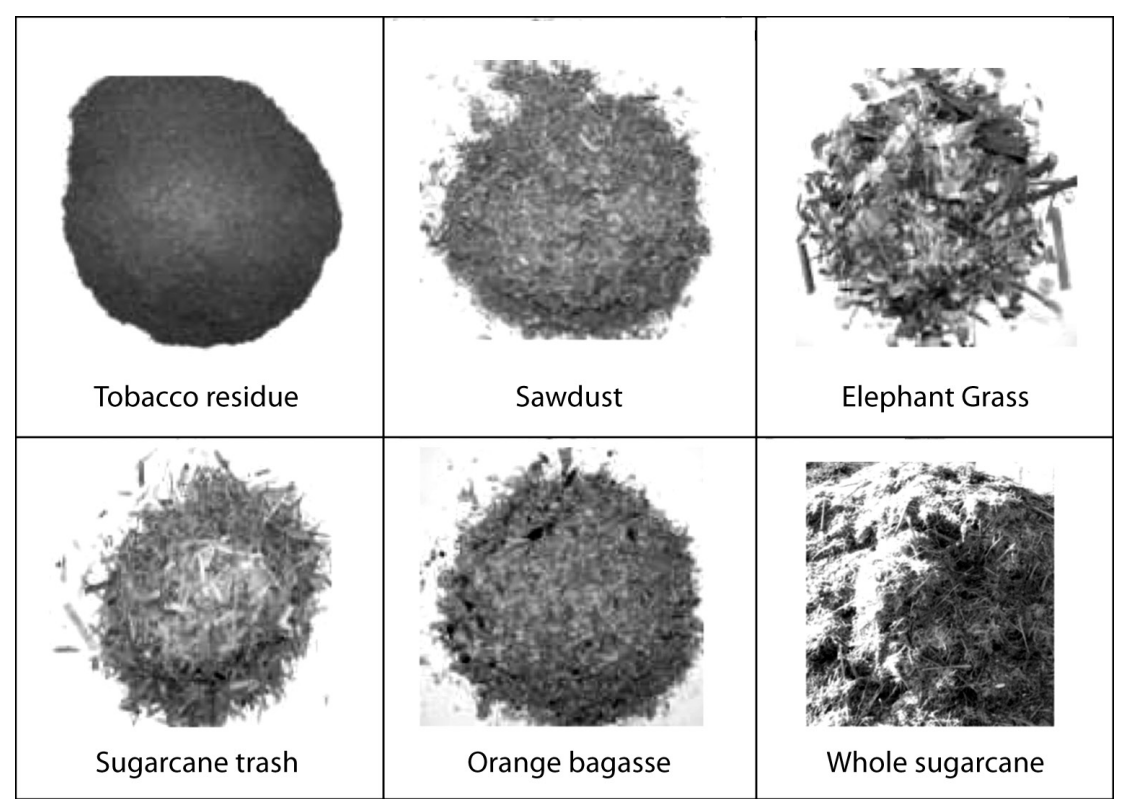

FIGURE 2 Raw materials processed at FEAGRI-UNICAMP pyrolysis pilot plant.

The fast pyrolysis of biomass aims to maximize the productivity of bio-oil. To acieve this, it is necessary to ensure that the biomass, used as raw material, has particles in the size range between 1 and $4 \mathrm{~mm}$ and water content up to 15\%. Figure 2 shows the physical features of some biomasses that were processed in the pilot plant.

\section{THE YIELD OF PYROLYSIS PRODUCTS}

The obtained yields from fast pyrolysis, in laboratory scale bio-oil recovery equipment, can reach up to $75 \%$ mass based (Table 1 ). This yield considers the total mass of recovered liquid, such as: water, acids, extractives and the bio-oil. In pilot plants of pyrolysis using air as fluidizing agent, the productivity of bio-oil (5\% to $7 \%$ of water), acid extract and charcoal, are showed on Table 2 . The used calculation basis corresponds to the dry organic matter in the fed biomass to the reactor. The organic matter is calculated subtracting the water amount and ashes in the biomass and, deducting the percentage of biomass that is combusted by the oxygen in the fluidization air. The use of air in the process of pyrolysis ensures the auto thermal operation of the reactor.

TABLE 1 Yield of the typical products obtained by means of different kinds of pyrolysis of wood (dry basis).

\begin{tabular}{|l|l|c|c|c|}
\hline \multicolumn{1}{|c|}{ Process } & \multicolumn{1}{c|}{ Process conditions } & Liquid & Charcoal & Gas \\
\hline Fast pyrolysis & $\begin{array}{l}\text { Moderate temperature }\left(450^{\circ} \mathrm{C} \text { to } 550^{\circ} \mathrm{C}\right) \text {, short time } \\
\text { of vapor residence }(0.5 \text { to } 3 \mathrm{~s}) \text { and biomass with low } \\
\text { granulometry. }\end{array}$ & $75 \%$ & $12 \%$ & $13 \%$ \\
\hline Carbonization & $\begin{array}{l}\text { Low temperatures }\left(400^{\circ} \mathrm{C} \text { to } 450^{\circ} \mathrm{C}\right), \text { long residence times } \\
\text { (it can be hours or days), large particles (pieces of wood). }\end{array}$ & $30 \%$ & $35 \%$ & $35 \%$ \\
\hline Gasification & High temperature $\left(900^{\circ} \mathrm{C}\right)$ & $5 \%$ & $10 \%$ & $85 \%$ \\
\hline
\end{tabular}


TABLE 2 Yield of pyrolysis products in the Feagri-Unicamp pilot plant using sugarcane trash (dry organic matter basis).

\begin{tabular}{|l|c|}
\hline \multicolumn{1}{|c|}{ Products } & Yield (\%) \\
\hline Charcoal & 20 \\
\hline Bio-oil & 30 \\
\hline Acid extract & 10 \\
\hline Gases & 40 \\
\hline
\end{tabular}

\section{FAST PYROLYSIS AS A PRETREATMENT STEP OF BIOMASS}

The fast pyrolysis has two features that are highly beneficial: (1) its main product is the biooil (liquid fuel) and (2). Technical and economical feasibility in a scale of 1 to 2 ton/h of biomass feeding. The bio-oil is the biomass in a liquid form, and this way, it has some advantages on transportation, pumping, storage and handling. These characteristics the solid biomass does not have because of the high water content. Thus the bio-oil can benefit of all the structure currently used for the liquid fuels. In what concerns the scalability, the fast pyrolysis plants have demonstrated to be much more efficient in a low scale. This way, the little plants or even mobile plants, can go near the biomass in the processing location, avoiding the expensive transportation of the biomass through long distances. The biomass in a liquid state, in other words, in the bio-oil form, is more convenient and feasible the long distance due to its high energy concentration, less humidity and characteristics of the liquid fuel. The economical availability of the small size plants is a differential of this technology that allows a decentralized use.

\section{PRIMARY ENERGY FROM BIOMASS}

The use of biomass as energy needs to consider the energy balance of the productive chain for its production and transformation afterwards. All the energy used for the production and packaging of biomass must be uncounted of its primary energy. In the diagram of the block displayed in Figure 3 there is a representation of the above mentioned. The advantage of primary energy of the whole sugarcane, for example, can be an interesting alternative regarding the use of the bagasse, the straw or the sucrose in an independent way.

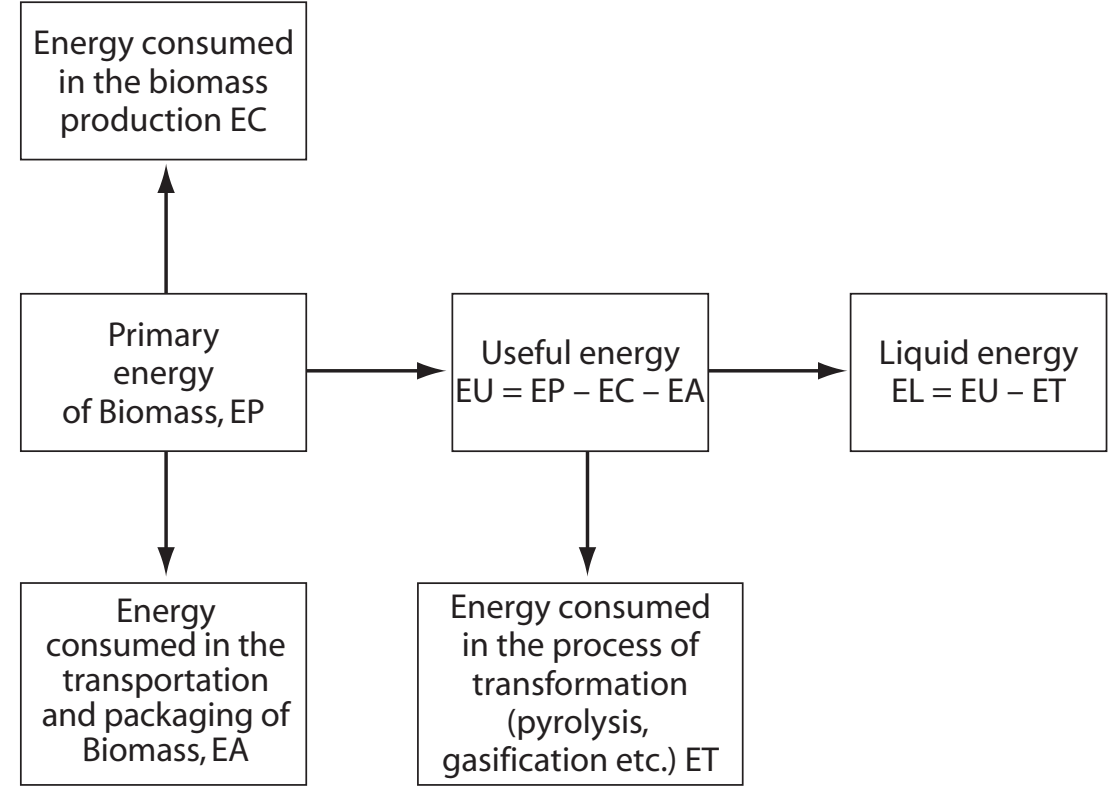

FIGURE 3 Diagram of the primary energy consumption in the productive chain of biomass transformation. 
These kinds of studies are recommended with the purpose of developing or upgrading techniques that allow to use in a more efficient way the primary energy of the sugarcane.

\section{POTENTIAL APPLICATIONS OF PYROLYSIS PRODUCTS}

All the products of fast pyrolysis has potentially important application even as intermediary in other industrial processes, as final product after chemical transformations to adapt to other applications or directly with renewable fuel, as showed in Figure 4. In all the applicable possibilities, the bio-oil is always a renewable substitute for fuels or raw materials traditionally resulting from fossil sources.

Studies are being performed, considering a scenario where the bio-oil will always be used as source for the production of synthesis gas. The bio-oil will be obtained in a fast pyrolysis plant in a fluidized bed in low scale and from a great variety of biomass available as residue of several agricultural, agro-industrial and agro forestry system. The mixture of all bio-oil production will be storaged in a large size plant to be gasified and to produce synthetic fuels, fertilizers and other products through catalytic synthesis, as showed in the chapter about BTL - biomass to liquids. This is a description of a biorefinery based on synthesis gas. Its structure must be of a large size since the catalysis plants are expensive and only justifiable for big volumes of production. This proposed model allows and justifies the use of fast pyrolysis in its best scale.

The gasification system can be easily pressurized and so oxygen can be use instead of using atmospheric air, so this is the main advantage on gasify the bio-oil. This method produces high quality synthesis gas because it avoids its dilution on nitrogen of the atmospheric air and results in high concentrations of two components of synthesis gas, the hydrogen and the carbon monoxide. In addition, the pressure to obtain the synthesis gas, when elevated, aids the following step of catalytic synthesis that needs the synthesis gas on high pressures, in the range from 50 to $100 \mathrm{~atm}$.

\section{BOTTLENECKS IN THE TRANSFORMATION STEPS OF BIOMASS PYROLYSIS}

The biomass to be the raw material in the process of fast pyrolysis must fulfill the requirements of particle size uniformity and water content. The first step is to deal with the logistics for the packaging of polydispersed biomass. Brazil, a particularly strong agricultural country, annually produces about 300 million tons of agricultural and agro industrial residues. However, only a small part is used as energy source, as these residues have poor energetic features (low density, low calorific power and high moisture), and then results in higher costs during transportation, handling and storage. In other words, the logistics for whole use of this residue in natura can be extremely expensive.

What is named as pretreatment of the biomass for the thermo-chemical conversion may be an industrial facility as big and expensive as the main process. To think about all the production stages of a biofuel is a task that can vary considerably depending on the kind of raw material and fuel that is intended to obtain.

All the productive chain of the biomass production has several operation units (collection, transportation, packaging, processing) that can make impracticable its use due to the high production costs. Thus, a forest raw material will have a different flowchart from the agricultural origins raw materials (straw, corn stalk, cassava stalk etc.), agro industrial (sugarcane bagasse, filter cakes etc.), livestock (manure, suet, poultry litter etc.), aquatic biomass (marine of freshwater) or urban waste (trees pruning, mud from sewer, organic waste). Besides, there are three types of fuel: solids, liquids and gases. And for each one of them these operations have a great variation.

The solid state is the most current type that the biofuels are found, have problems concerning the form diversity and particles size, high moisture and low energy density. The liquid state (vegetable oil, alcohols, biodiesel, bio-oil etc.), is the most practical way of biofuels, making easier its handling and the logistics. The gases, biogas, landfill 


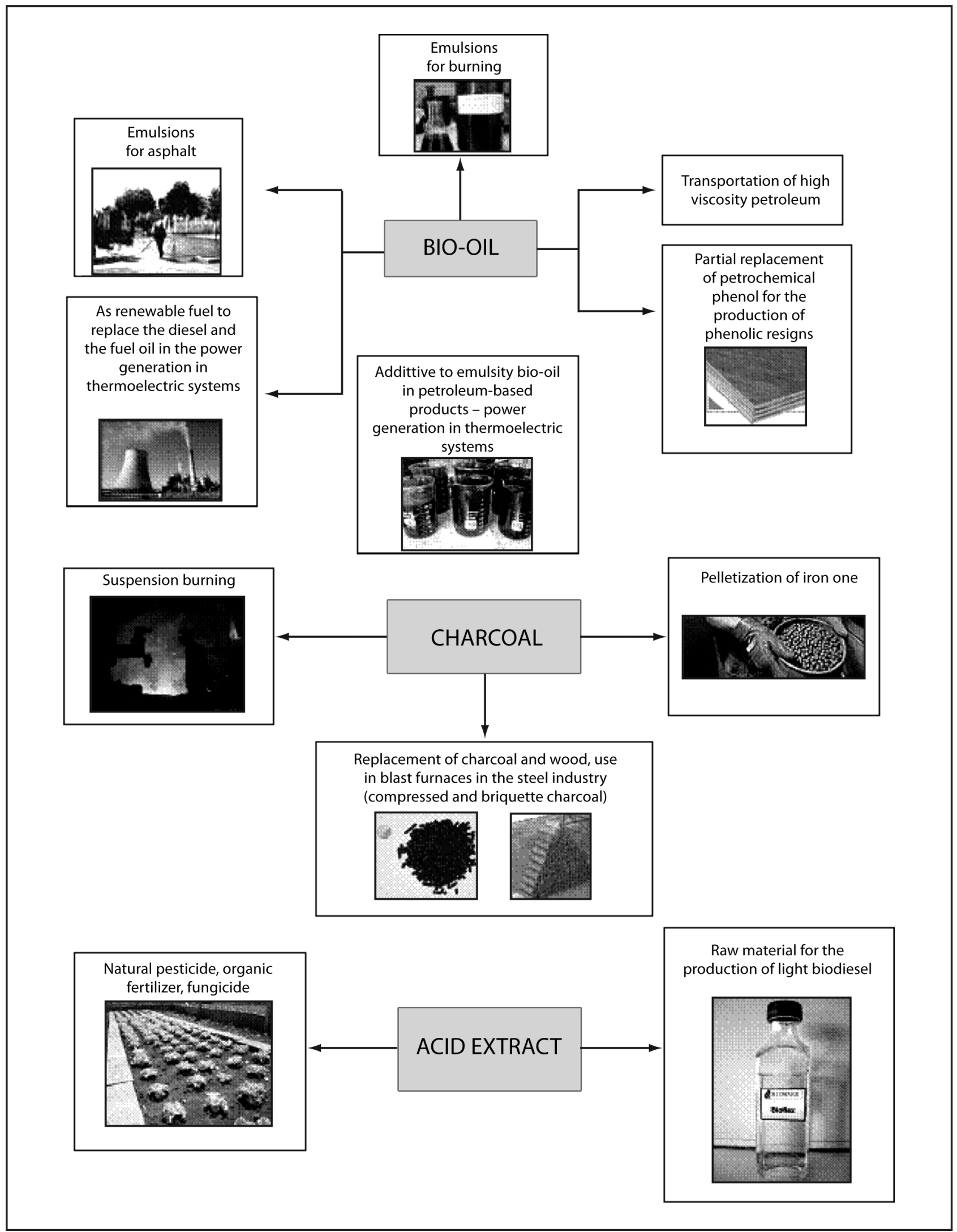

FIGURE 4 Fast pyrolysis products and its potential applications. 
gas and mud from sewer gas, besides synthesis gas, usually cannot be transported in long distances and should be used locally.

The bioenergy logic is very different from the logic of fossil energy. The bioenergy is linked to the concept of distributed generation and to small and middle scale plants because the fossile fuels, that is, the non renewable energy, the generation/ production is better centralized and is in a big scale. The mining stages (sourcing and exploring) of non renewable fuels are replaced by the agriculture stages in bioenergy and in agro energy. Generally, the biofuels are composed by oxygenated compounds without sulfur and the fossils are hydrocarbons $(\mathrm{C}$ and $\mathrm{H})$ and have sulfur as one of its main heteroatom. The presence of oxygen in the biofuels reduce its calorific power, however it grants a better burning quality, because already have intramolecular oxygen.

\section{LOGISTICS}

Biomass is logistics. A new biofuel/bioenergy production unit should carefully consider the availability of raw material in its coverage radius so that there is some savings in the process to be implemented. The way between the field of agricultural production and the area of raw material reception in the industrial plant must have a distance that does not charge the final cost of the biofuel/bioenergy above the acceptable level. The production cost depends on the case in study. The coverage radius of the sugarcane industry (for each manufacturing plant) is well-defined, the same way, the energy forests know its transportation costs.

\section{STORAGE}

Immediately after the harvest, the biomass goes to the storage, or alternatively, goes to processing that will originate a residue or co-product that shall be appropriately stored.

The storage stage can really be critical in the stage of the biomass pretreatment for the energy, it must be adequate to ensure the constant supply, avoid changes in the fundamental features of the raw material (decay, deterioration etc.) and allow, for instance, the loss of the needed moisture naturally.

Therefore, the residue must be treated as raw materials to avoid that during the handling occurs the incorporation of inorganic materials (land, stones etc.) that are unfavorable elements in any process of pre and post treatment. Essentially, in the case of planting of energy crops, as the case of the elephant grass, there is the need to face all agricultural process as a pretreatment of biomass not only about production yield by hectare (productivity), but also about the composition of the contents like: cellulose, hemicelluloses, lignin and ashes to assess its actual energetic potential in a specific technology.

\section{DRYING}

Biomass drying needs to be avoided or made in a natural way in the cases that the biomass is a residue normally spread. An example of this is the sugarcane trash that is dried in 3 days on its own land where it has been cut and transported in the form of bundles to the factory. In biomass packaging is the low production cost and to save as much of its primary energy that is important.

The appropriate storage can help in the loss of initial biomass moisture. Many processes usually have exceeding heat energy that can be used for drying. This is an advantage in plants attached to an existing manufacturing plant.

There are processes that take place in aqueous means, as the case of the biotechnological processes: fermentation, biodigestion etc., however for the thermal processes is important to have the dry biofuel or compatible moisture varying between $8 \%$ and $15 \%$, and for that, energy is required. Although in Brazil the sugarcane industry is gradually specializing in the direct bagasse burning with high moisture, other processes of thermo-chemical conversion like the fast pyrolysis and the gasification usually work with biomass with low moisture.

The availability of dryers in the Brazilian market is quite large. The equipment is dimensioned with capacities that vary from less than a ton to several tons per hour. These technologies are rotating bed, transportable bed, cyclonic bed, 
fluidized bed and even permanent bed (for wood), usually provided by several manufacturers.

\section{HOMOGENIZATION}

This stage comprises the following operations: picking, milling and sifting. These unit operations are used for the reduction and the standardization of the particles sizes. The fast pyrolysis demands the homogeneity of the particles and the control over the size distribution is necessary and critical, ensuring a strict range of sizes. The equipment like wood picking, ball, knife and hammer mills and vibrating sieve system are all equipment available in the Brazilian market with performance warranty of the manufactures.

\section{FAST PYROLYSIS}

Finally, the fast pyrolysis of the biomass to obtain bio-oil is the stage of transformation of the solid and low density biomass in a renewable combustible in the liquid state.

There is much debate and controversies around the plant scalability of fast pyrolysis of biomass. The Canadian companies use several technologies with high capacities installed, from 100 to 200 tons of biomass a day. However, these scales do not have a lot of success due to the complexity of the plants. In Brazil, the studies reached the scale of $200 \mathrm{~kg} / \mathrm{h}$ and the plant from 20 to 40 tons a day is possible to work satisfactorily. This scale is already designed; it is necessary investments for its construction as fundamental step of "scale up".

The great technological difficulties involved in the "scale up" are linked to the fluid dynamics of the reactor of fluidized bed that is complicated. Stable operations of the reactor (this is, pressure profile and temperature along the reactor in immobile regime) are only possible if the blend of the inert material and the biomass are appropriate. Located problems of temperature rise, sintering, gas leak are common when the fluid dynamic of the bed is not dominated. The increased scale, a situation equivalent to the increasing of the diameter of the reactor has the inconvenient in which the feeding point does not ensure the homogeneous blend of the biomass along the perimeter of the diameter of the bed. To put distributed feeding points may help to solve the problem, however the economical and financial aspects in the implementation of this solutions must be evaluated with caution. Parallelly use reactors may be a less risky practice.

Another technological bottleneck is the recovery of bio-oil which is accomplished by Canadian technologies that use electrostatic precipitators. The biomass transformation technology must be robust and easy to operate. The use of expensive equipment although efficient is not always viable when the subject is biomass. In Brazil there is a technology of centrifugal separators that, although operates with less productivity is robust and cheaper. We can say the same thing about the expensive pneumatic biomass feeding systems that in Brazil are replaced by screw feeders.

Pyrolysis occurs in atmospheric pressure and moderate temperatures (between $450{ }^{\circ} \mathrm{C}$ and $500{ }^{\circ} \mathrm{C}$ ), so, it is created operational conditions that make easier the construction and operation of the plants. Another variable is the residence time that must be short so that the vapors do not suffer intense cracking and the unwanted gasification of the bio-oil still in the vapor phase occurs, negatively affecting the productivity of this main fraction.

Considering that it is safe to reach a feeding rate up to two tons per hour (24 tons per day). A possible scenario is to produce the bio-oil in a decentralized and distributed way and to concentrate all production to be processed in a big gasifier, using oxygen and high pressures; this could be a beneficial arrangement.

Inside these operations of pretreatment, the use of energy (energy balance) and the water consumption (mass balance) for the preparations of the vegetal materials must also be considered, searching for the rational use and the energetic efficiency of the processes.

This arrangement can make viable the technology of fast pyrolysis of biomass in Brazil with the benefit of having a great availability of raw material and competitive costs. 
A common strategy to create the consumer market of an innovative product consists in the search of partnerships with the final consumer and the performing of market tests with the products derived from the technology. The partnership University-Company is essential in this stage.

\section{INVESTMENTS IN COMMERCIAL DEMONSTRATIVE PLANTS}

The technological necks associated with the change of scale can only be completely solved if resources are dedicated for the implementa- tion of plants of demonstrative pyrolysis (500 to $1000 \mathrm{~kg} / \mathrm{h}$ of biomass feeding). The scale change is also an innovation and a necessity to put the technology in the market and demonstrate its commercial viability. The investments in these stages contributed to the introduction of this technology in the short-term market by means of the production of samples and adequacy of the pyrolysis products in the consumer market. The technical-economic viability has already been demonstrated and the increasing of scale will prove commercial viability of the technology of fast pyrolysis in fluidized bed.

\section{REFERENCES}

BRIDGWATER, A. V. Fast pyrolysis of biomass: a handbook. [S.l.]: Aston University, Bio-energy research group, UK, 2002. v. 2.

CORTEZ, L. A. B.; LORA, E. E. S.; GÓMEZ, E. O. Biomassa para energia. Campinas: Editora da Unicamp, 2008. v. 1. $736 \mathrm{p}$.

MESA-PEREZ, J. M Teste em uma planta de pirólise rápida de biomassa em leito fluidizado: critérios para sua otimização. Tese (Doutorado) - Feagri, Universidade Estadual de Campinas - Unicamp, 2004.

ROCHA, J. D.; MESA PEREZ, J. M.; CORTEZ, L. A. B. Aplicação dos Produtos da Pirólise Rápida de Biomassa como Fertilizante Natural (in Potuguese) Capítulo 13 p. 397-408 do livro Fertilizantes: agroindustria e sustentabilidade Editores: F. E. Lapido-Loureiro, R. Melamed; J. Figueiredo Neto, do Cetem, 2009. 